\title{
Tourist Industry Promotion: Aim to Introduce Thai Local Foods Matching With Northern Program’s Tours to Serve Sustainable Tourism
}

\author{
Surachai Jewcharoensakul \\ Kasetsart University, Bangkok, Thailand
}

\begin{abstract}
Tourist industry had been promoted and become one of the important strategies of Thai government for socioeconomic development for years and become successful by ranking-Thailand becomes well-known as top ranking to visit from tourists around the world. When people travel, foods are always needed to fulfill human needs and the satisfaction of the travelers. The objectives of the research were to: (1) survey and determine the local food image and identity of Northern region of Thailand to support tourist industry; (2) survey program's tourism in Thailand and study the promotion of local food that had added in the programs' tours as tourist destination; (3) find out the possibility of local food and culture for promotion in tourist industry of Northern region in Thailand; (4) develop gastronomy tourism's routing. The population were the subject persons who are experts in tourist industry, Northern foods restaurant owner, and program's tour. Mixed method was used for data collection and analysis. The result of the research is revealed into four parts: Phase 1: (1) Thai Northern region had been divided into two part: upper Northern and lower Northern region. There are eight provinces in upper Northern region: Chingmai, Chingrai, Lampoon, Lampang, Prayao, Phare, Nan, and Mae-Hongsorn. Chingmai was the capital of "Lanna territory (1558-1774)” rich with culture; (2) Upper Northern local foods related to the legend, have their own characters and are still available to get to eat; (3) Northern local food contained with Northern ingredient and indicated as geographical indications; (4) The lower Northern region related with "Sukhothai territory (1157-1370)", Sukhothai was the capital. There are six provinces in the region: Sukhothai, U-taradid, Tag, Kampangpet, Pidsanuloak, and Petchaboon. Food of the lower Northern provinces had their own characteristics but some of the dishes were influenced with Chinese cuisine, such as noodles. Phase 2: Most of tour companies had included local food in the tour programs to promote Northern local foods in low level. Phase 3: Life's pathway of the Northern people lived related to the three seasons: rainy season, cool season, and summer. Each season had different kinds of vegetables and fruits which influence the menus and foods. Eating foods as medicine also related to the season, such as shallot and garlic had added more in foods in cool season, in order to prevent cold of family's members. Northern life style always celebrated in all ceremonies with foods, snack, and sweet, such as: wedding, cremation, and community cerebrations which may be promoted in tour program as their ways of living with sustainable, in order to promote socioeconomic development in the community. Phase 4: The gastronomy tourism was developed into five routings to promote tourist industry in the Northern part of Thailand as the following: (1) gateway to reach "Lanna”; (2)
\end{abstract}

Surachai Jewcharoensakul, Ph.D., associate professor, Vocational Education Department, Faculty of Education, Kasetsart University, Bangkok, Thailand.

Correspondence concerning this article should be addressed to Surachai Jewcharoensakul, Vocational Education Department, Faculty of Education, Kasetsart University, 10900, Bangkok, Thailand. 
window to visit the Northern part of Thailand; (3) pay respect to the Buddha and visit dynasty heritage; (4) visit the peaceful and tranquilly heritage; and (5) visit Thailand's border with boundless. Conclusion: Thai local lifestyle, culture, and local foods in the Northern part of Thailand, contained rich image and identity of history, legend, and human diversity, which are worth and valuable for promoting as tourist industry in the Northern part of Thailand and also conserved job absorption and community development. Therefore the government of Thailand and tour companies ought to promote Thai local foods as value added and tourist industry which also benefit for the sustainable socioeconomic development in long future.

Keywords: Thai tourism promotion, foods image, Thailand Northern Culinary

\section{Introduction}

Tourist industry had been promoted and become one of the important strategies of Thai government for socioeconomic development for years and become successful by ranking - Thailand becomes well-known as top ranking to visit from tourists around the world. Thailand became independent for more than 1,400 years since Tavaravadee regime in the century of 5-11 (Danai \& Chiyotha, 2007), and the empirical evidences existed at Wat Pramane in Nakorn-Prathom province in the Western part of Thailand. The UNESCO (United Nations Education, Science and Cultural Organization) had nominated world heritage sites in Thailand of culture or natural heritage (https://en.wikipedia.org/wiki/List_of_World_Heritage_Sites_in_Thailand) as the following. There were three culture of world heritage sites, such as: (1) Historic Town of Sukhothai and Associated Historic Towns (1991), (2) Historic Ancient City of Ayutthaya and Associated Historic Towns (1991), and (3) Ban Chieng Archaeological Site (1992). As Thailand is one of the old countries, we had been collecting such culture, art, crafts, ceremonies, and uniqueness of human lifestyles that are valuable to learn as world heritage site of culture. The UNESCO had also nominated World heritage site of natural in Thailand, such as: (1) Thungyai-HuaiKhaKhang Wildlife Sanctuaries (1991), and (2) Dong Phayayen-KhaoYai Forest Complex (2005). Thailand is located in Southeast Asia with tropical climate. Thailand is one of the suitable place for growing diversity of plants and trees in the tropical climate area and the diversity of birds and animals.

When people travel, foods are always needed to fulfill the human needs and gain satisfaction of the travelers. In fact, tourist industry development had provided job opportunities due to the socioeconomic development in community and nation. But local foods hadn't been introduced in the Northern tour programs and hadn't supported the local people well enough. Then the study of "Tourist industry promotion: Aim to introduce Thai foods matching with northern program's tours to serve sustainable tourism” is important in order to introduce the country of Thailand to the world, introducing Thai local foods to strengthen Northern Thai foods image and provide sustainable tourism and sustainable development of education and socioeconomic development in communities and nation as well.

\section{Objective of the Study}

The objectives of the research were to:

(1) Survey and determine the local food image and identity of Northern region of Thailand to support tourist industry.

(2) Survey program's tours in Thailand and study the promotion of local food had added in the programs' tours as tourist destination. 
(3) Find out the possibility of local food and culture for promotion in tourist industry of Northern region in Thailand.

(4) Develop gastronomy tourism routing of the Northern part of Thailand.

\section{Expected Benefits}

(1) Thailand Tourism and Sport Ministry may have learned and got an idea to promote local foods as tourist destination in the Northern and other regions of Thailand, in order to promote education and socioeconomic development for communities and nation as sustainable tourist industry development, such as: community protection, education development, and jobs creation, would have benefited local and country side area.

(2) "Explode from inside" was educated by the present King of Thailand and King Bhumiphol, in order to remind the Thai government officers to work the plan of community's development by using participatory action research and subject matters of the key persons to develop the community's needs which should come from their own in the community.

(3) Teaching and learning about tourist industry development needed to be concerned of all sectors in tourist industry process, in order to provide job opportunity for people in the roll.

\section{Scope of the Study}

This study indicated the scope of the study within the following:

Area of the study was in the Northern part of Thailand, including 14 provinces, which were divided into two parts: (1) upper northern region, there are eight provinces: Chingmai, Chingrai, Lampoon, Lampang, Prayao, Phare, Nan, and Mae-Hongsorn, and (2) lower northern region, there are six provinces: Sukhothai, Kampangpet, Tag, Pidsanuloak, U-taradid, and Petchaboon.

\section{Literature Review}

Reynolds (1993) said the key success factors of providing gastronomy tourism needed to concern the target populations, promoting the local foods, and concern the local culture as well. Beardsworth and Keil (1997) agreed that eating foods not only provides nutrition for human health but may educate and gain experiences of the tourists, and also show the identity of the social as well. Ryan (1997) said the eating behavior of tourists found that local foods in such tourist destination provided the satisfaction for the tourists and affected the tourists to return back in such place.

Karim (2006) studied about gastronomy tourism effect on the promotion of tourist destination, and he found that foods street in Thailand was interesting, as there were such variety of foods, cheap price, and good taste. Nield, Kozak, and LeGrays (2000) had studied about food service and foods satisfaction of the tourists in Romania, and they found that the European tourists and Romanian tourists satisfied foods and foods' service in the same direction, such as: foods' price, quality of foods, services, the varieties of foods, garnishing, the fastness of service, and atmosphere of the restaurant.

Quan and Wang (2004) studied about the relation of food consumption and the satisfaction of traveling experience, and they found that the tourists satisfied consumed foods during traveling in higher level than the traveling experience and suggested that foods service in tour destination may promote tourist industry. Cohen and Avieli (2004) studied the key success factors for promoting tourist industry, and they had found that sanitation, quality of foods, and good service were important key success factors. 


\section{Research Method}

(1) The population were the subject persons who expert in tourist industry and Northern foods restaurant owners.

(2) The Northern tour's programs were used for analyzing to find out the possibility of providing Northern gastronomy tourism.

(3) Mixed method was used for data collection and analysis.

\section{Research Result}

The result of the research is revealed into four parts:

\section{Phase 1}

(1) There are 14 provinces of Thailand Northern region. Northern region of Thailand had been divided into two parts: upper Northern and lower Northern region. There are eight provinces in upper Northern region, such as: Chingmai, Chingrai, Lampoon, Lampang, Prayao, Phare, Nan, and Mae-Hongsorn. Chingmai was the capital of "Lanna territory (1558-1774)", which was rich with culture, art, crafts, ceremonies, and uniqueness of their own lifestyle of living.

Upper Northern local foods related to the legend of Lanna territory, have thier own characters and are still available to get to eat. Some foods are influenced by Myanmar's food, such as "Nam-prig Ong” and "Hang-ley curry”, were created by Myanmar. "Khao-Soy” or curry egg noodle had been eaten in every province of the upper Norther region. "Nam-Ngew" or curry without coconut milk which serves with ferment noodle always served lots of different varieties of fresh vegetable for breakfast, and people still enjoy eating now. These kinds of food were used for introducing Northern foods in all occasion. In any ceremony and celebration of the Northern, people always provided foods to make satisfaction of all the guests and audients. One of the Royal food's ceremonies, in Lanna regime, called "Kan-Thoak Dinner" served with the show of traditional dances had been provided to the Northern tour's program and always made the tourists enjoy the program and gain experiences with good memorandum and also provide such kind of jobs to the local people.

Northern local food contained Northern ingredient and indicated as geographical indications, such as "fermented soy bean powder" using for season, "Nam-Pu = crab plate" using for season, which is completely different from the seasoning of the other part of Thailand. The taste of foods in upper Northern part contained mine taste. Some kinds of foods existed only in the Northern part of Thailand, due to the ingredient of vegetable and cooking method, such as "Kae curry" cooked with vegetable that grown in the Northern part of Thailand in cool weather, can be served in cool season, November to January. "Kang Hoa” mixed stir-fried left over foods recooked with mung bean noodle and green cabbage pickle, was one of the sufficient economy food and was accepted to all, as delicious Northern food.

(2) The lower Northern region related with "Sukhothai territory (1157-1370)" Sukhothai was the capital. There are six provinces in the region: Sukhothai, Kamphaeng, Phet, Tag, Pidsanuloak, U-taradid, and Petchaboon. UNESCO had nominated Historic Ancient City of Sukhothai and Associated Historic Towns located at Sukhothai and Kamphaeng Phet Provinces, in the central part of Thailand, was nominated in 1991, the size is 29,290 acres. This world heritage which was well-known with the historic city and town, is in some part of lower Northern part of Thailand. The lower Northern part of Thailand was close to the Central part of Thailand and culture was influenced by the foreigners, such as French, Portugal, English, and Chinese. In this 
area many stoves to make ceramics were found and some technique of China bone ceramic was found. According to the history, in the stone inscription it found that Sukhothai regime had traded and related with the Western countries.

Foods of the lower Northern provinces had their own characteristics but some of the dishes were influenced by Chinese cuisine, such as noodle, "Roast red pork" served with noodle, and mince pork served with noodle, because Sukhothai regime had done a lot of trading with China. Unfortunately, none of foods in the lower Northern provinces was influenced by the Western's cuisine; even they had traded and related with the Western countries for years.

There were not many varieties of foods' menu and choices in the lower Northern prat of Thailand, comparing to the upper Northern part of Thailand. One of the amazing foods, "Vichien-Buri Grilled Chiken" was a kind of grilled chicken that had been sold in every province in the Northern part of Thailand 14 provinces. It was originated from Petchaboon province, at Vichien-Buri district. Vichien-Buri grilled chicken had unique style of sauce or dip to serve with grill chicken. It contained tamarind which is geographical indication of fruit in Petchaboon province. Pechaboon province was very well-known with sweet tamarind. The research of Jidsamran (2012) had studied about the component and indicators of tamarind that had become sweet, and found that tamarind becomes sweet because of the soil, climate, and hybrid of the tamarind.

\section{Phase 2}

Surveying program's tours in Thailand and studying the promotion of local food had added in the programs' tours as tourist destination, which found that most of tour companies had provided and included local food in the tour programs to promote local foods done in low level.

All most two fifths of the tours' companies in the Thailand (39.10\%) had been established in Bangkok, the capital of Thailand, because Bangkok was well-known for tourist destination. More than one third (35.41\%) were established in the Southern part of Thailand, because the beach in the Southern part of Thailand was famous with white sand beach, bright and nice sunshine, and had beautiful view, 17\% were established in the Northern part of Thailand (Table 1).

Table 1

Tour's Companies Established in Thailand $N=3,506$

\begin{tabular}{lll}
\hline Tour's companies in Thailand & Amount & Percentage \\
\hline Bangkok & 1,371 & 39.10 \\
Central part of Thailand & 159 & 4.54 \\
Upper northern provinces & 437 & 12.46 \\
Lower northern provinces & 54 & 1.54 \\
Upper northeastern provinces & 26 & 0.75 \\
Lower northeastern provinces & 41 & 1.17 \\
Eastern provinces & 175 & 4.99 \\
Western provinces & 1 & 0.03 \\
Upper southeastern provinces & 275 & 7.84 \\
Lower southeastern provinces & 967 & 27.58 \\
Total & 3,506 & 100.00 \\
\hline
\end{tabular}

There were almost a half of the tour's companies in Thailand located in the central part of Thailand (43.94\%), in which Bangkok is the capital, more than one third of the tour's companies located in the southern 
of Thailand (35.42\%). According to the interviewing of the tour's companies owners, they found that most of the tourists always stop as the first destination in Bangkok, then extend traveling to the country side later, even though the tourists always travel to the northern part of Thailand, but, still purchase programs tours form Bangkok.

Southern provinces had more tour's companies changed because of direct flight to the South of Thailand, then the tourist could fly directly to southern part instead of starting from Bangkok, also due to the good reputation of tourist destination in the southern part, such as Puket, Krabi, and Trang with beautiful natural resources, peaceful beach, and nice bright sunshine. The reason why Eastern provinces have more tour companies might be because the government indicated the Eastern part of Thailand to be manufacturing and heavy industry plant, which effected to the economic growth and more international companies from abroad came to settle heavy industry plant, in the Eastern part of Thailand. In the Northeastern part of Thailand indicated as not wealthy area for years, because of the low quality of soil land and limited of rain water for cultivation, but the government had improved infrastructure and so on (Table 2).

Table 2

Tour's Companies Located in the Different Part of Thailand $N=3,506$

\begin{tabular}{lll}
\hline Tour's companies in Thailand & Amount & Percentage \\
\hline Bangkok and central part & 1,531 & 43.94 \\
Northern provinces & 491 & 14.00 \\
Northeastern provinces & 67 & 1.92 \\
Eastern provinces & 175 & 4.99 \\
Southeastern provinces & 1,242 & 35.42 \\
Total & 3,506 & 100.00 \\
\hline
\end{tabular}

Northern provinces of Thailand, had been divided into two parts: (1) Upper Northern provinces located in the hill and mountain sight areas, which were separated by the geography land scape and related to the history of Lan-Na territory, and Chiengmai was the capital. They had their own speaking and writing language, culture, and ceremony, before became ruled by the Ayuthaya and Rattanakosin regime of Siam, then the country of Thailand; (2) Lower Northern provinces located in geography of flat land, but only Pechaboon province, located in the hilly and mountain area. All the six provinces in lower Northern provinces had related to the history of Sukhothai regime, and Sukhothai was the capital of Thailand for 213 years, at Christian era of 1157-1370 (the country of Siam, then Thailand was ruled by Sukhothai regime, then Ayuthaya regime, Thonbury regime, and Rattankosin, at the present). The characteristics of language and human being of people at the lower Northern were quite different from such characteristics in the upper Northern part of Thailand.

\section{Phase 3}

The study found that Northern tours' programs had promoted Northern culture quite well, but local foods still not had shown in the tour's program, except the "Kan-Toak dinner".

Life's pathway of the Northern people lived related to the three seasons: rainy season, cool season, and summer. Each season had different kinds of vegetables and fruits which influence the menus and foods. Eating foods as medicine also related to the season, such as shallot and garlic which had been added more in foods in cool season, in order to prevent cold of family's members. Northern life style always celebrated in all ceremonies with foods, snack, and sweet, such as: wedding, cremation, and community cerebrations which may be promoted 
in tour program as their ways of living with sustainable, in order to promote socioeconomic development in the community.

Symbol and characteristics of food in the Northern provinces of Thailand, indicated as culinary tourism in future found that foods and characteristics of upper Northern provinces had influenced by Lan-Na regime, hill type people, and Myanmar's cuisine, ingredients, and cooking processes, such as: Khao-soi (noodle served in curry soup), Nam-ngew (noodle served with curry without coconut milk), Hung-ley curry (influenced with Myanmar's cuisine), Sai-uaow (Thai northern sausage), Care curry, Lab, Ho curry (mixed leftover foods), Nampic-Ong dip, Nampic-Noom dip, and Oorm curry. In the upper Northern provinces people always eat glutinous rice (sticky rice) instead of steam rice. "Khan-Tok dinner” was very well-known of Lan-Na Royal cuisine, and was served as a set of dinner individually. The local foods in the lower Northern provinces were influenced by Chinese cuisine, such as noodle, roast red pork, and mince pork. Also many dishes of fish, because this part of Thailand located in the river site and dam.

\section{Phase 4}

The gastronomy tourism was developed into five routings with the Northern tourist destination and gastronomy tourism, in order to promote tourist industry in the Northern part of Thailand, as the following:

First routing "Gateway to reach Lanna”, introduced three provinces of Petchaboon, Pitsanuloak, and U-Taradit provinces, included the historical areas, natural sites, culture, and gastronomy of: (1) "Vichienburi grill chicken”, the sauce to serve with contained with geographical indication, tamarind; (2) fermented noodle served with five different kinds of sauces and fresh vegetable, those two dishes were served in Petchaboon province; (3) "Thai noodle” food that was influenced by Chinese cuisine, served in Pithsanuloak province; (4) "Khao Pan Paj (rice film wrapped with noodle and vegetable)" served in U-Taradit province besides such a dished cooked with different kinds of fish.

Second routing "Window to visit the Northern part of Thailand", introduced three provinces of Sukhothai, Kampangpet, and Tark provinces. Sukhothai was the capital of "Sukhothai regime" with rich of historical areas of world heritage site "Sukhothai and associated town" which nominated by UNESCO in 1991. The routing also introduced the natural site, natural sites, and gastronomy of: (1) "Khao Perp” (old style Thai noodle) and "Thai noodle” served in Sukhothai province; (2) "Cha-Kanglaos noodle” served in Kampangpet province; (3) three well-known dished in Trak province was influenced by hill type people and Chinese cuisine; (4) "white bean curry, stir-fired vegetable with fermented soybean and rice film salad”.

Third routing "Pay Respect the Buddha and Visit theDynasty Heritage", introduced three provinces: Chiengmai, Lampang, and Lampoon provinces. Chiengmai was the capital of Lanna regime. These three provinces are rich with Lanna culture, art, crafts, and ceremonies. The routing introduced the historical area, natural sites, included tracking of ecotourism of hill type people and mountain's jungle. Gastronomy of this route was introduced: (1) Khan-Toak dinner, the Royal cuisine of Lanna regime, served in Chiengmai; (2) "longan fruit noodle" served in Lampoon province. These three provinces also had lots of local Northern dishes, such as: "Khao soy noodle”, “Lab-Khaow”, “Nam-Neaw noodle”, “Sai-Uoaw”, “Nam-Prig Oong”, "Nam-Prig Noom”, crispy pork skin always served as side dish and so on.

Fourth routing "Visit the Peaceful and Tranquilly Heritage”, introduced three provinces: Praa, Nann, and Pra-Yaow. These three provinces were known as peaceful sites, clam people, rich with culture, art, crafts, and ceremonies. The routing introduced the historical area, natural sites of badland of wind erosion in Praa province. Gastronomy of this routing was introduced: (1) "galangal herb dip" to serve with grill fish; (2) "kai (fresh water 
seaweed) salad"; (3) "wild fruit drink". These three provinces also had served many ways of cooking dished with fish, because there is a big fresh water lake in Pra-Yaow province.

Fifth routing "Visit Thailand's Border with Boundless", introduced two provinces of Chiengrai and Mae-Hongsorn. Chiengrai is located as the top roof of Thailand, to connect Laos and Myanmar. Mae-Hongsorn is located to connect with Myanmar. These two provinces are in the highland area of mountain with many group of hill type people. There are 11 different groups of hill type people in Thailand, such as: Karieng is the biggest group, besides there are Mong, Yaow, Muser, Lee-Sor, Arr-Kha, Louw, Thai-Leu, Thai-Yai, Chin-Hor, and Pa-Long. In each group of the hill type people, they have their own language, culture and living style, but all of them believed in ghost and spirit. Foods of the hill type people had not been introduced to the restaurants as much as supposed to, because cooking method, serving style, taste and hygienic had not contained such ingredients to be accepted yet. Gastronomy of this routing was introduced to some food that influenced hill type people cuisine, such as "Khaopook (rice with black sesame seed)", "Khao Ram-Fern”, "Kang Gadang (solid curry)”, "Kang-Hoa (re-cooked dish with mixed left over foods)”, and "Hang-Ley curry” which was influenced by Myanmar cuisine.

\section{Discussion}

Gastronomy tourism development in Thailand is needed to develop in more location and perspectives, because Thailand country had such varieties of culture with long period of history, as well as could develop for community to be part of the tourist industry development in order to maintain and empower the community with sustainability in long future.

\section{Conclusion}

Thailand country is an old country for more than 1,400 years old. It had been collected and conserved such culture, lifestyle, art, crafts, and ceremonies. Thailand was known as "Siam country" located in Southeast Asia. The Northern part of Thailand was in "Lanna regime" in which Chiengmai province was the capital, they had their own culture, contained rich image and identity of history, legend, and human diversity and foods, which are worth and valuable for promotion as tourist destination and gastronomy tourism also conserved job absorption and community development by the way of socioeconomic sustainability development.

\section{Suggestion}

The government of Thailand and tour companies ought to realize the possibility and potential of Thailand Northern local foods and promote foods as gastronomy tourism, which would have value added in tourist industry, in order to provide food image and food identity in such area for such a good memorandum for the visitors in such area.

Gastronomy tourism would have benefited for the sustainable of socioeconomic development in long future.

Geographical indication of fruits, vegetable, and ingredients could be promoted to value added to the tourist industry and provide satisfaction to the tourists.

\section{References}

Beardsworth, A., \& Keil, T. (1997). Sociology of the menu. London: Routledge.

Chiyotha, D. (2007). Thai history and culture. Bangkok: Odeon Store. 
Cohen, E., \& Avieli, N. (2004). Food in tourism: Attraction and impediment. Annals of Tourism Research, 31(4), 755-778.

Jidsamran, P. (2012). The component and indicators of Tamarind had become sweet Tamarind. Petchaboon: Petchabun Rajabhad University.

List of World Heritage site in Thailand. UNESCO: from https://en.wikipedia.org/wiki/.

Nield, K., Kozak, M., \& LeGrays, G. (2000). The role of food service in tourist satisfaction. Hospitality Management, 19, 375-384, New York University.

Ongsakul, S. (2001). Lanna History. Bangkok: Ammarin Printing Co. Ltd.

Reynolds, P.( 1993). Food and tourism: Towards an understanding of sustainable culture. Journal of Sustainable Tourism, 1(1), 48-54.

Ryan, C. (1997). Recreational tourism: A social perspective. London: Rout ledge.

Quan, S., \& Wang, N. (2004). Towards a structural model of tourist experience: An illustration from food experiences in tourism. Tourism Management, 25, 297-305.

Karim, M. S. A. (2006). Culinary tourism as a destination attraction: An empirical examination of the destination's food image and information sources. Dissertation: The Oklahoma State University.

Yazawin, Z. (2003). Chronicle of Chaing Mai. Yangon: University Historical Research Centre. 